\title{
Public Comment Periods and Federal Environmental Impact Statements: Potentials and Pitfalls from the American Experience
}

ERICA MORRELL

Volume 1, Fall 2013

DOI: http://dx.doi.org/10.3998/mjs.12333712.0001.008

\section{ABSTRACT}

Public comment periods are a primary mechanism for engaging citizens in Environmental Impact Statement (EIS) processes and, in turn, federal decisions with significant environmental, economic and cultural impacts. Yet citizens often feel disenfranchised throughout the five main stages of these comment periods. As a result, when members of the public participate in public comment periods, they are increasingly doing so not only to provide feedback on a given proposed project but to critique the nature of civic engagement and democratic decision-making occurring today. EIS public comment periods are thus at times transforming from a means of enhancing the sustainability of federal actions to a civic tool for challenging what are viewed to be exclusive governance practices. Improving the dynamics of public involvement in EIS public comment periods by engaging citizens earlier, developing clearer guidelines for incorporating civic input into decision-making, diversifying EIS preparers, and moving public comment periods to a deliberative model can enhance democratic engagement and the environmental, economic and cultural sustainability of future government actions.

The National Environmental Policy Act, adopted into law in 1970 and arguably the most comprehensive environmental legislation in the United States to this day, requires federal agencies to consider and generate detailed assessments of the potential environmental, economic and socio-cultural impacts of proposed government actions through the preparation of an Environmental Impact Statement (EIS) prior 
to making any decisions about whether to move forward with such activities. What makes this mandated EIS process different from some other decision-making efforts is the requirement that all interested parties, including state agencies, tribes, and other affected groups and members of the public, be invited to provide input throughout parts of the EIS process largely as part of required 'public comment periods' - sanctioned times during which the public has at least forty-five days between the release of a draft and final EIS to review and remark on proposed federal actions and alternatives. Officials and the public often (in theory) support engagement in these comment periods as a means to create comprehensive and inclusive decisions that best mitigate harm to the environment, economy, and society and thus lead to more sustainable federal activity overall.

Today, public comment periods are one of the most frequent and widespread forms of direct citizen engagement decision-makers employ. They foster participation in federal regulation on issues from innovative breakthroughs in biotechnology and energy extraction to the more mundane construction of new roads and pipelines and are commonly led by the Department of Interior, the Department of Energy, and the Department of Agriculture. In 2011 alone, 442 EISs were filed with the Environmental Protection Agency (EPA) - each involving its own public comment period. On any given day, there are thirty to sixty open public comment periods across the U.S. as part of an EIS process (Environmental Protection Agency 2012a).

Despite the broad use, admirable purpose and concrete achievements of EIS public comment periods over the past forty years, scholars, practitioners and other citizens also have criticized this engagement mechanism. First, some argue that such public comment periods allow citizens to remark on how to regulate federal actions but not to question or prevent such activities more generally (Ferretti and Pavone 2009). Public participation in this respect simply offers citizens the opportunity to react to plans, decisions, and technologies already in the making, rather than preventing them in the first place (Jasanoff 2005). Second, many scholars and members of the public claim that certain values and forms of knowledge-such as the traditional knowledge of Native Americans-are overlooked or misinterpreted by decision-makers, who are better skilled in understanding and interpreting more technocratic perspectives (Stevenson 1996). Third, both public and private actors have launched critiques against the design and implementation of public comment periods, from arguing that they are too brief to allow for sufficient engagement, to claiming that they engage so many perspectives that valuable resources are spent on irrelevant comments (Coglianese 2006; Steelman and Ascher 1997). Finally, others have expressed frustration over the fact that the National Environmental Policy 
Act does not actually prohibit agencies from making decisions that may defy public concern (within the constraints of the law); final decisions around a proposed project can lawfully go against the public input obtained throughout an EIS public comment period.

Because of these issues, EIS public comment periods-especially those held around more controversial projects like drilling on Native American lands or the genetic modification of foods intended for human consumption-haved faced wellpublicized crises of legitimacy across many sectors of the public. In these situations, activists and other citizens have participated in public comment periods not only to provide feedback on a given proposed project but also to remark on the quality of democratic decision-making. EIS public comment periods are thus, in these instances, transforming from a means of enhancing the sustainability of federal actions to a civic tool for challenging what are viewed to be insufficient governance practices.

The following sections of this article outline the main weaknesses in engagement as they exist during the five major stages of EIS public comment periods and provide evidence of how citizens contest each stage's shortcomings to challenge the legitimacy of EIS decision-making more broadly. After illuminating these problems and the emerging public response, I introduce four suggestions for improving the EIS public comment process: (1) engaging citizens earlier, (2) developing clearer decision-making guidelines for incorporating civic input, (3) diversifying EIS preparers, and (4) moving public comment periods' design from a participatory model to a deliberative one. Improving EIS public comment periods can enhance the ability of the U.S. government and public to work together in addressing proposed federal activities, quelling civic dissatisfaction and more effectively mitigating possible hazards associated with government actions - ultimately leading to more sustainable federal activity.

\section{The Five Stages of Public Comment Periods: Shifting Focus from Proposed Actions to Civic Engagement}

Despite the differences and complexities inherent in each individual EIS public comment period, there are five primary stages common to these periods, all of which offer opportunities to successfully engage the public or to create barriers to citizen inclusion (see Table 1). Citizens who feel inadequately represented in a comment period-from low-income immigrants to prosperous business owners, depending 
TABLE 1. Public Involvement: The Five Main Stages of EIS Public Consultation Periods

\begin{tabular}{|c|c|c|c|c|c|}
\hline Stage & 1: & 2: & 3: & 4: & 5: \\
\hline Activity & $\begin{array}{l}\text { Determine whether } \\
\text { to conduct a public } \\
\text { comment period }\end{array}$ & $\begin{array}{l}\text { Draft public } \\
\text { consultation } \\
\text { documents }\end{array}$ & $\begin{array}{l}\text { Hold public } \\
\text { comment period }\end{array}$ & $\begin{array}{l}\text { Analyze and } \\
\text { respond to } \\
\text { comments }\end{array}$ & $\begin{array}{l}\text { Decide on } \\
\text { proposed action }\end{array}$ \\
\hline $\begin{array}{l}\text { Public } \\
\text { Involvement }\end{array}$ & $\begin{array}{l}\text { Generally } \\
\text { no public } \\
\text { involvement }\end{array}$ & $\begin{array}{l}\text { "Scoping period" or } \\
\text { solicitation of input }\end{array}$ & $\begin{array}{l}\text { Comment } \\
\text { submission and } \\
\text { (at times) hearings }\end{array}$ & $\begin{array}{l}\text { Generally } \\
\text { no public } \\
\text { involvement }\end{array}$ & $\begin{array}{l}\text { Generally } \\
\text { no public } \\
\text { involvement }\end{array}$ \\
\hline $\begin{array}{l}\text { Proposed } \\
\text { Intervention }\end{array}$ & $\begin{array}{l}\text { Establish more } \\
\text { diverse EIS } \\
\text { preparers; } \\
\text { engage citizens } \\
\text { earlier }\end{array}$ & $\begin{array}{l}\text { Foster deliberative } \\
\text { engagement; } \\
\text { institute clearer } \\
\text { guidelines for } \\
\text { effectively } \\
\text { including citizen } \\
\text { input }\end{array}$ & $\begin{array}{l}\text { Foster deliberative } \\
\text { engagement }\end{array}$ & $\begin{array}{l}\text { Institute clearer } \\
\text { guidelines for } \\
\text { effectively } \\
\text { including } \\
\text { citizen input }\end{array}$ & $\begin{array}{l}\text { Institute clearer } \\
\text { guidelines for } \\
\text { effectively } \\
\text { including } \\
\text { citizen input }\end{array}$ \\
\hline
\end{tabular}

on the case-may capitalize on the inadequacies of such periods and transform them into a tool for protesting the nature of engagement in decision-making today. Examining the public's reaction to and use of EIS public comment periods thus reveals much about both emerging forms of contemporary activism and weaknesses in federal citizen engagement.

The federal agency that proposes an activity subject to a mandated EIS typically appoints a group of scientific and technical experts, from biologists to engineers, to manage the EIS public comment period. This lead agency may select the people to to manage this process, as well as determine how they are selected; the lead agency often draws from its own staff as well as the public and private sectors. There is little regulation or standardization across agencies or issues in this process of designating preparers, but for various reasons — such as time, cost and efficiency-appointed preparers tend to be from relevant sectors of the government and industry; only rarely does an agency request and involve others, such as academics, in this process. While all comment periods tend to follow the same general steps, then, there is room for variation across preparers, agencies, and proposed actions. Moreover, even if on the surface every stage appears similar, each EIS comment process is laden with the knowledge, values, and views particular to the distinct experts involved in a particular EIS's design and implementation. As other perspectives try to enter the process once public comment periods are underway, conflicts may emerge since these 'expert' teams often determine what knowledge is relevant to the EIS process and can consequently overlook, misinterpret and/or exclude perspectives that are different from their own, as discussed below (Stevenson 1996). When values and 
expectations clash, members of the public may strategically shift away from commenting on a given proposed action to instead criticizing the nature of the EIS public comment period itself.

\section{Determining Whether to Conduct an EIS Public Comment Period}

In the U.S., federal agencies proposing an action subject to the jurisdicion of the National Environmental Policy Act are required by this Act to prepare an Environmental Assessment that outlines the possibility for the proposed activity to have environmental, social and economic impacts. From this brief Environmental Assessment, the responsible federal agency determines if the potential impacts are great enough to warrant the preparation of an EIS and accompanying EIS public comment period. In cases where private industry is undertaking a major project and a federal agency is merely responsible for permitting the action, the private entity itself may prepare an essentially complete assessment that is finalized upon acceptance by the reponsible federal agency. Typically the public is not engaged in either the assessment or the decision-making that takes place during this Environmental Assessment process. The National Environmental Policy Act does not mandate citizen participation during this time, and most entities preparing Assessments lack the procedures and incentives necessary to foster public involvement (Jain 2002).

For example, in the recent and ongoing case of genetically modified salmonpotentially the first engineered animal permitted for human consumption-the Food and Drug Administration relied on the company responsible for creating the fish, Aqua Bounty Technologies, Inc., to prepare the Environmental Assessment (largely without public engagement). The resulting assessment demonstrated few potential negative impacts and outlined mitigating measures for any possible concerns, leading the Food and Drug Administration to subsequently deem it unnecessary to prepare an EIS and host a related public comment period. In reaction to public exclusion from the assessment's preparation and ensuing decisions about the EIS public comment period, numerous rallies, protests and other forms of outcry and opposition have taken place. In fact, eleven U.S. Senators and twenty-eight U.S. Representatives urged the Food and Drug Administration to suspend its approval process until more meaningful public engagement has been achieved (Defazio et al. 2010). Additionally, Earthjustice, on behalf of the Ocean Conservancy, Friends of the Earth, and the Center for Food Safety, among others, submitted a citizen petition urging the Administration to conduct an EIS and involve the public (Kimbrell et al. 2011a). As this case suggests, members of the public who are frus- 
trated by their exclusion from the Environmental Assessment process may demand a greater role in this critical stage and ensuing EIS decision-making.

\section{Drafting Public Consultation Documents}

If upon reviewing the Environmental Assessment findings the federal agency spearheading the EIS process deems it necessary to prepare an EIS and hold an EIS public comment period (unlike what occurred in the abovementioned case), that agency must release a Notice of Intent in the Federal Register that opens a 'scoping period.' During this scoping period, members of the public and other stakeholders can provide the agency with input concerning the issues to be covered in the draft EIS. Upon the close of this scoping period, an agency-appointed team of preparers then employs its discretion to determine the overall process of the draft EIS, including if and how the public's input during the scoping process should guide the draft EIS's subsequent design, what facts are relevant and should be incorporated into the document, and how information is presented, worded and explained-generally with no outside accountability. Draft EISs are thus prepared according to the values and forms of knowledge specific to the team of expert preparers at the expense of other perspectives (Irwin 2001). Once published, this draft EIS becomes the primary document on which public comment periods are based and serves as the main source of information on proposed federal actions in response to which the public may comment.

In a case involving the ownership and sale of engineered seed of all varieties, for example, a team comprised mostly of scientific and technical experts drafted the consultation document for an ensuing public comment period. Upon the document's release and the opening of the comment period, many members of the public felt the technical wording and overall nature of the document excluded citizen perspectives that had been presented during the scoping period and precluded the participation of members of the public who lacked the expertise necessary to fully comprehend the document. They claimed that this led to "controversial interpretations of the propos[ed] project" particularly with respect to a 'farmer's privilege' clause, which permits some forms of seed-saving under the Plant Variety Protection Act and case law stemming from Asgrow Seed $v$. Winterboer. Indeed, in this case the technical wording around the proposed action's extension of certain forms of intellectual property rights led many members of the public to interpret the 'farmer's privilege' clause as threatened (Prentice-Hudson 2010). Resulting concerns over the protection of the farmer's privilege were thus expressed extensively in the com- 
ments submitted during the period, detracting attention from the proposed action itself yet highlighting disparities in inclusion in the preparation of the consultation documents. Ultimately, public outcry persuaded the government to delay moving forward with the action (Prentice-Hudson 2010). As this case illustrates, members of the public may feel disenfranchised throughout the EIS draft preparation process and respond with hostility as consultation documents are prepared and/or released (Lauber and Knuth 1998).

\section{Holding a Public Comment Period and Releasing the Consultation Document}

As a public comment period opens, the spearheading agency must determine how to notify the public and invite their participation. Public consultations are advertised in English (and other languages if the spearheading agency deems it necessary) in government notices in the Federal Register, associated government websites, and at times newspapers, radio stations, television advertisements and/or other media such as flyers on commuity bulletin boards. The methods used to alert the public of a comment period can constrain and enable participation, shaping who knows about and has access to the comment period-at times further limiting the participation of already marginalized sectors of the population such as the disabled, minorities, and low-income groups.

For example, in the case of the Black Mesa coal mining operation on and near Navajo, Haulapai and Hopi tribal lands, the Office of Surface Mining sent letters directly inviting eleven agencies potentially affected by the proposed project to participate in the EIS public comment period, including government and tribal entities, and advertised the period in English via media releases, paid newspaper notices, and radio announcements (Office of Surface Mining Reclamation and Enforcement 2008a). Yet contention quickly developed among the public concerning issues such as the "lack of notification of numerous local Navajo people and interested stakeholders" about the public comment period and the "inaccurate and incomplete" translation of EIS documents into indigenous languages. Many aggravated members of the public then aired these concerns throughout the related public comment period, causing an extensive portion of the remarks received during this period to shift away from discussing the proposed mining changes to instead critiquing the nature of citizen engagement (Office of Surface Mining Reclamation and Enforcement 2008b).

Additionally, with the release of a draft EIS and the opening of a public com- 
ment period comes the determination of when and how long the period will be held and if associated public hearings will take place (and, if so, where, when and how). In the Black Mesa case mentioned above, the Office of Surface Mining held twelve public hearings across Arizona and Nevada in early 2007 and extended the original 45-day comment period by an additional several weeks (Office of Surface Mining Reclamation and Enforcement 2008a). Still, many citizens who commented during the public comment period expressed general frustration with the hearings, complaining that the "format, length, and availability of public meetings were not adequate to capture community input into the process." Additionally, many stakeholders raised concerns over "the occurrence of public meetings during the Hopi winter ceremonial season" and when weather caused a "lack of passable roads on the reservation," among other concerns (Office of Surface Mining Reclamation and Enforcement 2008b). Again, then, comments condemning aspects of public participation within the EIS process, in addition to and instead of the proposed mine itself, became the focus of much of the comment period and ensuing decision-making. And this is true in many other cases as well. Hosting an EIS public comment period and any associated hearings around religious and cultural holidays has become controversial across many different EIS processes, as have issues related to general access, such as the feasibility of attending public hearings and the way hearings are run, among other issues.

\section{Analyzing and Responding to Comments}

While the National Environmental Protection Act requires the agency leading an EIS process to incorporate and respond to comments received during public comment periods in the preparation of a final EIS, it is up to the team responsible for preparing the EIS to determine the level of consideration given to each received comment. This tasks preparers with the broader responsibility of deciding if and how public input is incorporated into subsequent EIS preparations. The inclusion of public feedback into the final EIS is thus left to the subjective decision-making of a small team of appointed experts and often differs from EIS to EIS, agency to agency, and proposed action to proposed action. In some cases, minor or no changes may be made between the draft and final EIS; in other cases substantial changes may be made and, if drastic enough, can lead to the preparation of a supplemental EIS or an entirely new draft EIS and public comment period. At a minimum, most agencies summarize comments and provide a response, attach all comments to any subsequent EIS document, and make these components available to government agencies and the public. 
In the case of genetically modified Roundup Ready alfalfa, for example, when the U.S. Department of Agriculture deregulated the crop following an EIS process, the Center for Food Safety and Earthjustice filed a lawsuit against the Department on behalf of ten additional groups, including the Sierra Club, Center for Food Safety, and Beyond Pesticides. This suit argued that the Department's final EIS failed to include and consider certain perspectives, forms of knowledge and information concerning potential impacts that the public had raised in the comment period, such as discounting and failing to fully consider possible impacts of trangenic contamination on conventional and organic farmers, businesses and the public and not adequately assessing the potential for the release of Roundup Ready alfalfa to lead to a decline in other alfalfa varieties. The resulting EIS document, the suit argued, was "based on unreliable data and erroneous assumptions contrary to the record" (Kimbrell et al. 2011b). Leveraging inadequacies in the EIS public comment period, civil actors thus sued the Department and broadened the EIS discussion (and use of resources) from a focus on the sustainability of the proposed federal action itself to the issue of the quality of democratic participation. As this case illustrates, the variable and ill-defined standards for incorporating received public comments into subsequent stages of the EIS can generate concern and contention among commenting citizens who question if and how their input affects ensuing EIS preparations and come to believe their participation is undervalued.

\section{Deciding on the Proposed Action}

Thirty days after an EIS public comment period closes, comments are analyzed and responded to and the final EIS is released; at this time, the agency responsible for the proposed action can decide if it will move forward and how. In theory the EIS and any incorporated public feedback from the comment period should guide this decision, and often the public believes it will. In actuality, however, there is no requirement for the content of public comments to shape governance decisions: the National Environmental Policy Act simply requires that federal agencies understand and disclose the potential impacts of a proposed action but does not prohibit agencies from making decisions that may harm one or all three pillars of sustainability - the environment, economy and society (within the constraints of the law). Thus, while many federal agencies certainly do try to use the EIS to aid in decision-making, there are few exemplary frameworks, guidelines, or regulations to assist in such efforts since it is not mandated.

For example, in 2008, the Department of the Interior completed an EIS public 
comment period and reached a subsequent decision concerning actions around oil shale and tar sands leasing in the American West. In response to this decision, the Wilderness Society along with ten other organizations, including the Center for Biological Diversity, Natural Resources Defense Council, and Environment Colorado, submitted a letter of protest to the Department for, in part, releasing a decision that "deprived" public input from shaping "the agency's analysis of environmental impacts, the resulting decisions ... and the logic of proceeding" (Morgan et al. 2008). Rallies, marches and other forms of protest accompanied this letter and reflected these concerns. Again, the nature of democratic engagement in the EIS public comment period was criticized and questioned, becoming a focus of the decision-making in addition to the sustainability of the proposed project itself. And this case is not an anomaly: decisions about whether and how to move forward with proposed actions following the preparation of an EIS have in numerous situations become contentious as members of the participating public come to realize their input may not influence decision-making.

\section{Improving the EIS Public Comment Process}

As the above discussion highlights, inadequacies with democratic engagement around EIS public comment periods may become the focus of EIS processes, causing attention to be targeted at contesting and addressing the nature of citizen engagement in addition to, and sometimes rather than, the sustainability of proposed federal activities. In turn, officials and citizens spend scarce resources (including money and time) on protesting, negotiating, litigating and strategically maneuvering around public comment issues and not directly at mitigating the potential negative consequences of government actions. At times, citizen challenges are resolved in a manner that improves public engagement and the official treatment of sustainability in decision-making. In these cases, the calculated civic use of public comment periods as a tool for critiquing the quality of democratic engagement can lead to beneficial outcomes in terms of both participation and the reduction of harmful impacts resulting from proposed federal projects. However, in other instances where agencies tactically circumvent civic challenges or resolve them without any serious changes to prior inadequacies, federal actions may simply move forward without the meaningful public input that could make these projects more environmentally, economically, and culturally sound.

Addressing these shortcomings and improving the quality of engagement and 
the sustainability of federal activities will require multiple targeted actions and broader changes in the design and implementation of EIS public comment periods across all five main stages. Below are a few important steps along these lines, though others should be considered and will likely be necessary.

(1) Citizens need to be engaged earlier in the EIS public comment process, including in the initial Environmental Assessment stage that helps determine if an EIS should be carried out at all (Doelle and Sinclair 2006). As the above discussion highlights, without earlier and enhanced inclusion citizens will likely continue to feel disenfranchised by the EIS public comment process, and potentially critical perspectives will be precluded from informing decision-making (Portman 2009).

(2) Clearer expectations, standards and guidelines need to be developed so that decision-makers have the direction and directive to more effectively incorporate civic input into proposed federal actions. Currently, decision-makers are not required to use public comment period input to guide decisions about whether and how to move forward with federal projects, and, furthermore, there are few voluntary methods for helping agencies successfully use such feedback in decision-making. Fostering a widespread, comprehensive understanding of how public feedback can and should shape decision-making and creating effective steps for the implementation of best practices will ultimately enhance citizen inclusion and, likely, the sustainability of ensuing actions.

(3) A standard for more diverse EIS preparers must be established. Typically a given agency appoints a small team of scientific and technical experts to run the entire EIS and EIS public comment period. Academicsparticularly social scientists - are often excluded from critical EIS preparations academics. Also frequently marginalized are individuals from the at-risk groups most affected by proposed federal actions, such as indigenous populations, low-income groups, and minorities. Until these actors have power in actual EIS design, implementation and decision-making, the true potential for democratic inclusion in limiting the negative environmental, economic and cultural impacts of federal activities will remain unrealized.

While it is difficult to find the right balance of diverse preparers, some studies suggest that even the addition of one non-technical expert to a committee like those responsible for the EIS process can ultimately 
foster more representative and effective decision-making. For example, the Canadian Biotechnology Advisory Committee includes one citizen member who has helped the Committee better consult the public and integrate effective deliberative processes, such as consensus conferences that bring lay citizens together to identify key issue areas, cross-examine experts, and agree upon a position to present to policymakers and the general public (Einsiedel, Jelsoe and Breck 2001).

(4) Opportunities for broad citizen engagement in EIS public comment periods should be based on a model of deliberative democracy instead of participatory democracy. The current participatory concept that underlies comment periods advocates a largely one-way model where citizens provide input upon which decision-makers may or may not draw. Deliberative approaches encourage authentic two-way deliberation and open dialogue between the public and those holding power within government (Endres 2009). Moving to a model of deliberative EIS public comment periods, possibly first through public hearings, would help decisionmakers and citizens come together to measure alternative perspectives and arguments against one another to achieve more inclusive and effective decision-making. Transforming the EIS public comment process to a deliberative model could thus minimize contention and maximize positive outcomes (Berkhout, Leach and Scoones 2003).

Indeed, members of the public frequently feel more engaged in and satisfied by deliberative processes than participatory ones, and decisionmakers often reach more informed decisions through such processes. For example, community dialogue models of deliberative democracy were employed in Eugene, Oregon, Sacramento, California, and Fort Collins, Colorado concerning issues ranging from balancing the municipal budget to managing community growth. Each dialogue varied in structure but generally consisted of inviting community members to public meetings and community workshops through advertisement and recruitment methods similar to those employed in EIS public comment processes. At the first such meeting, attending participants discussed and identified core issues with the proposed policy to present to decision-makers. Next, decision-makers directly engaged citizens in developing alternatives to the proposed policy through ongoing structured discussions that produced a small set of feasible, promising alternatives to mitigate potential problems with the existing government proposal. Finally, decision-makers for- 
mally drafted a proposal that included the original policy and identified alternatives and distributed it to the public via community workshops and citizen surveys. In the workshops, decision-makers and community participants again debated the policy options and alternatives to prioritize a final action. By completing surveys, citizens could also rank their preferences regarding the final action. Workshop deliberations and survey feedback then combined to inform final decision-making (Weeks 2000).

Academics responsible for researching the above dialogues generally found them to be effective in achieving broad representation from interested groups, informed public engagement, deliberative participation and credible results (Weeks 2000). Of course, deliberative processes are not without their own drawbacks. Among other concerns, these processes can be time consuming, fail to reach consensus, and attract few participants; furthermore, they are even more difficult to conduct nationally than in distinct regions or municipalities (Ryfe 2005). Nonetheless, nondeliberative public consultation periods share some of these challenges and may even need to be conducted two or three times if the public successfully deems the first round of consultation insufficient. For example, in the case of the EIS public consultation regarding the oil shale and tar sands leasing, contention over the inadequacy of public engagement forced the federal government to conduct a second EIS process or face le-

gal repercussions. Insufficient engagement thus caused the EIS processes in this case to take over four years (Bureau of Land Management 2012). Deliberative processes, which appear to foster more legitimate public participation, may therefore ultimately be less time-consuming and costly (financially and in terms of the public's trust) than standard public consultations.

The Benefits of Improving EIS Public Comment Periods: Implications for Engagement and Sustainability

Changing the EIS process, specifically EIS public comment periods, will not be easy-indeed such broad-level policy change rarely is. Yet with sustained and serious efforts on the part of the public (who must place pressure on elected and appointed officials for change), federal agencies and other entities dealing with proposed actions within their jurisdiction (who can begin voluntarily incorporating 
many of the above recommendations), and executive leadership (who can mandate specific improvements to EIS public engagement), it is possible to achieve a more representative and effective EIS system (Environmental Protection Agency 2012b).

The potential rewards of improving EIS public comment periods are multiple. First, it will enhance the nature of democratic engagement in EIS public comment periods so that governments and publics can better work together in addressing proposed federal actions. Second, it can, in turn, lead to more legitimate and sustainable government activity in the U.S. Third, it is a step toward generating more democratic and sustainable actions across the globe, as governments around the world continue to draw upon components of and lessons from the American EIS experience in developing their own legislation. Indeed, while the U.S. was the first nation to mandate EIS preparations and public comment periods, today over one hundred countries have in place some form of environmental impact assessment and citizen engagement mechanisms. For example, even the People's Republic of China, where citizens are often shut out from government policymaking domains, has enacted environmental impact requirements with expanded rights for civic participation adapted from the American EIS model (Moorman and Ge 2007). Improving the U.S. EIS public comment process thus has important positive implications for participation and environmental, economic and cultural reform both here and abroad.

\section{References}

Berkhout, Frans, Melissa Leach, and Ian Scoones. 2003. Negotiating Environmental Change:New Perspectives from Social Science. London: Edward Elgar Publishing Limited.

Bureau of Land Management. 2012. "Proposed Land Use Plan Amendments for Allocation of Oil Shale and Tar Sands Resources on Lands Administered by the Bureau of Land Management in Colorado, Utah, and Wyoming and Final Programmatic Environmental Impact Statement." U.S. Department of the Interior. doi No. Fes 12-41.

Coglianese, Cary. 2006. "Citizen Participation in Rulemaking: Past, Present and Future." Duke Law Journal 55: 943-68.

Defazio, Peter, Dennis J. Kucinich, Mike Thompson, George Miller, Peter Welch, Lynn Woolsey, Jackie Speier, Barbara Lee, Sam Farr, Jerrold Nadler, John Garamendi, James Moran, David Wu, Maurice Hinchey, Earl Blumenauer, Betty McCollum, Madeleine Bordallo, Raul Grijalva, Dennis Moore, Donna Christensen, Lloyd Doggett, Lois Capps, Louise Slaughter, Kurt Schrader, Keith Ellison, Norman Dicks, Jim McDermott, Steve Rothman, and Barney Frank. 2010. Letter to Commissioner Hamburg. September 29.

Doelle, Meinhard, and A. John Sinclair. 2006. "Time for a New Approach to Public Participation 
in EA: Promoting Cooperation and Consensus for Sustainability." Environmental Impact Assessment Review 26:185-205. http://dx.doi.org/10.1016/j.eiar.2005.07.013

Einsiedel, Edna F., Erling Jelsoe, and Thomas Breck. 2001. "Publics at the Technology Table: the Consensus Conference in Denmark, Canada, and Australia." Public Understanding of Science 10: 83-98. http://dx.doi.org/10.1088/0963-6625/10/1/306

Endres, Danielle. 2009. "Science and Public Participation: An Analysis of Public Scientific Argument in the Yucca Mountain Controversy." Environmental Communication 3 (1): 49-75.

Environmental Protection Agency. 2012a. "Environmental Impact Statement Database.” Accessed November 28, 2012. http://www.epa.gov/compliance/nepa/eisdata.html.

. 2012b. "EPA Insight Policy Paper: Executive Order \#12898 on Environmental Justice." Accessed November 24, 2012. http://www.epa.gov/fedfac/documents/executive_order_12898. htm.

Ferretti, Maria Paola, and Vincenzo Pavone. 2009. "What Do Civil Society Organizations Expect from Participation in Science? Lessons from Germany and Spain on the Issue of GMOs." Science and Public Policy 36 (4): 287-99. http://dx.doi.org/10.3152/030234209X436527

Irwin, Alan. 2001. "Citizen Engagement in Science and Technology Policy: A Commentary on Recent UK Experience.” PLA Notes 40:72-75.

Jain, R. K. 2002. Environmental Assessment, $2^{\text {nd }}$ ed. New York: McGraw-Hill.

Jasanoff, Sheila. 2005. Designs on Nature: Science and Democracy in Europe and the United States. Princeton, NJ: Princeton University Press.

Kimbrell, Andy, Erich Pica, Wenonah Hunter, Charles Margulis, Gretchen DuBeau, Angela Sanfilippo, Bob Waldrop, Eli Penberthy, Alexis Baden-Mayer, Esq., Boye Thorne Miller, and Alfredo Quarto. 2011. Letter to Dr. Hamburg. December 19.

Kimbrell, George A., Paige M. Tomaselli, Kateryna I. Rakowsky, and Paul. H. Achitoff. 2011. "Complaint for Declaratory and Injunctive Relief." United States District Court for the Northern District of California.

Lauber, Bruce T., and Barbara A. Knuth. 1998. "Refining Our Vision of Citizen Participation: Lessons from a Moose Reintroduction Proposal." Society and Natural Resources: An International Journal 11 (4): 411-24. http://dx.doi.org/10.1080/08941929809381091

Moorman, Jesse L., and Zhang Ge. 2007. "Promoting and Strengthening Public Participation in China’s Environmental Impact Assessment Process: Comparing China’s EIA Law and U.S. NEPA." Vermont Journal of Environmental Law 8:281-335.

Morgan, Ann, Mike Chiropolos, Amy Mall, Amy R. Atwood, Peter Hart, Steve Bloch, Bruce Gordon, Keith Hay, Erin Robertson, Rich McClintock and Peggy Utesch. 2008. Letter Re: Resource Management Plan Amendments for Oil Shale and Tar Sands Leasing and Production (73 Fed. Reg. 51838-51840, September 5, 2008) Failure to Provide Opportunities for Protests and Consistency Reviews. October 6. http://wilderness.org/sites/default/files/legacy/ Oil-shale-Protest-Letter.pdf

Office of Surface Mining Reclamation and Enforcement. 2008a. "Black Mesa Project Final Environmental Impact Statement: Volume I-Report."

2008b. "Black Mesa Project Final Environmental Impact Statement: Volume IIComments and Responses."

Portman, Michelle. 2009. "Involving the Public in the Impact Assessment of Offshore Renewable Energy Facilities.” Marine Policy 33: 332-38. http://dx.doi.org/10.1016/j.marpol.2008.07.014 
Prentice-Hudson, Elizabeth. 2010. Interview by Erica Morrell. June 15.

Ryfe, David M. 2005. "Does Deliberative Democracy Work?” Annual Review of Political Science 8: 49-71. http://dx.doi.org/10.1146/annurev.polisci.8.032904.154633

Steelman, Toddi A., and William Ascher. 1997. "Public Involvement Methods in Natural Resource Policy Making: Advantages, Disadvantages and Trade-offs." Policy Sciences 30: 71-90. http:// dx.doi.org/10.1023/A:1004246421974

Stevenson, Marc G. 1996. "Indigenous Knowledge in Environmental Assessment.” Arctic 49 (3): 278- 91 .

Weeks, Edward C. 2000. "The Practice of Deliberative Democracy: Results from Four LargeScale Trials." Public Administration Review 60 (4): 360-372. http://dx.doi.org/10.1111/00333352.00098 